\title{
Application of Hybrid Process of Coagulation/Flocculation and Membrane Filtration for the Removal of Protozoan Parasites from Water
}

\author{
Letícia Nishi, Angélica Marquetotti Salcedo Vieira, \\ Ana Lúcia Falavigna Guilherme, Milene Carvalho Bongiovani, \\ Gabriel Francisco da Silva and Rosângela Bergamasco
}

Additional information is available at the end of the chapter

http://dx.doi.org/10.5772/51287

\section{Introduction}

Contamination of water resources, especially in areas with inadequate sanitation and water supply, has become a risk factor for health problems (Fundação Nacional de Saúde [FUNASA], 2003), with water playing a role as a vehicle for transmission of biological agents (viruses, bacteria, and parasites) as well as a source of contamination by chemicals (industrial effluents).

Among the waterborne diseases, enteric diseases are most frequent. Approximately $19 \%$ of waterborne gastroenteritis outbreaks in the United States are attributed to parasitic protozoans (Lindquist, 1999), particularly Giardia and Cryptosporidium species, due to their wide distribution in the environment, high incidence in the population, and resistance to conventional water treatment (Iacovski et al., 2004).

Despite regulations and control measures turning to be more and more stringent, outbreaks of waterborne Cryptosporidium spp. and Giardia spp. have been reported worldwide (United States Environmental Protection Agency [USEPA], 1996; Centers for Disease Control and Prevention $[C D C], 2006)$. Therefore, the treatment applied to the collected water must ensure that it is free of pathogens and chemicals that pose health risks, when distributed by the water supply system. Furthermore, physicochemical parameters must meet the drinking water standards required by the laws of each country (Bergamasco et al., 2011). Thus, there is great importance in either the development of more sophisticated treatments or the improvement of the current ones. 
Due to its small size and resistance to chlorine disinfection, conventional processes used in water treatment systems are unable to remove or inactivate efficiently all (oo)cysts of these protozoans, depending, among other factors, on concentration of (oo)cysts in water and the integrity of the water treatment plants. In addition to these microorganisms, many other impurities can harm human health if not reduced or eliminated. These impurities do not approach each other, it is necessary to add a coagulant.

Chemical coagulants are the most used and among them the most common is aluminum sulfate, since it is cheap and easily obtained. However, chemical coagulants have certain disadvantages, as they require tight control over their residual concentration in treated water for human consumption as well as in industrial food production. The possibility of trace aluminum contamination in food, as well as undesirable damage to the human body, especially the nervous system, are scientifically proven facts and subject of constant and innovative medical research worldwide, which increasingly requires a rigorous control of the presence of metals in both drinking water and groundwater (Ndabigengesere \& Narasiah, 1998; Rondeau et al. 2000).

One alternative that arises in this context is the use of natural coagulants that have advantages over chemical coagulants since they are biodegradable and non-toxic, and produce sludge in less quantity and with lower metal content. Seeds of Moringa oleifera Lam (moringa), which contain active agents with coagulant properties, are an example of natural coagulants.

Moringa oleifera is a tropical plant belonging to the family of Moringaceae (Katayon et al. 2006). This plant is native to India, but is now found in other tropical regions (Bhatia et al. 2007), and it is drought tolerant. It has nutritional, medicinal and water coagulant properties. The seeds have an active compound that acts in colloidal systems, neutralizing charges and forming bridges between the particles. This process is responsible for floc formation and subsequent sedimentation (Ndabigengesere et al., 1995; Nkurunziza et al., 2009).

Studies have shown that moringa seeds have coagulation properties for treating effluents, as well as water. The seeds can be prepared either in water or in saline solution, removing color, turbidity, and total and thermotolerant coliforms (Nkurunziza et al., 2009; Madrona et al., 2010).

The use of coagulants for drinking water treatment, in spite of being efficient in the removal of most contaminants, is not able to generate water of high potability standards, which leads to the necessity of the simultaneous use of other techniques. Membrane filtration technique is already widely recognized and can be implemented in combination with coagulation processes.

The NOM found in the liquid leads to membrane fouling, flux reduction and inferior effluent quality. Therefore, the application of coagulants for the raw water pretreatment may bring about an improvement in permeates quality. This is very important, especially in the case of drinking water production. Conjunctive use of coagulation and membranes is 
becoming more attractive for water treatment because the coagulation is an opportunity to join NOM with other particles present in water before NOM reaches the membrane surface.

This way, this chapter will look at the use of alternative techniques for water treatment based on the use of natural coagulant (moringa seeds) associated with the membrane filtration process (microfiltration) to obtain Giardia spp. cysts, Cryptosporidium spp. oocysts, color and turbidity removal of surface water.

\subsection{Cryptosporidium spp. and cryptosporidiosis}

The oocyst is the stage transmitted from an infected host to a susceptible host by the faecaloral route. Routes of transmission can be (1) person-to-person through direct or indirect contact, possibly including sexual activities, (2) animal-to-animal, (3) animal-to-human, (4) water-borne through drinking water or recreational water, (5) food-borne, and (6) possibly airborne (Fayer et al., 2000). The water-borne transmission depends by the level of environmental contamination, survival of the oocysts to environmental conditions (Robertson et al., 1992), and oocyst resistance to a variety of methods used to water treatment (Korich et al., 1990) as chlorination, ozonation or incomplete removal of the oocysts by filtration methods. The disease is caused by protozoan parasites of genus Cryptosporidium spp., intracellular coccidian parasite.

According to Neves (2005), the genus Cryptosporidium has been recognized in 1907 by Tyzzer, to designate a small coccidia found in the gastric glands of mice, with specific name of C. muris. Subsequently, in 1911, the same author found another species, lower than the first, located in the small intestine of mice, and described as C. parvum. Other species have been described in various animals and humans, but studies about the biology, morphology and low specificity that this coccidian has with respect to the hosts, led most researchers to consider them as synonyms of $C$. muris e C. parvum. In recent years this concept has undergone changes due to the use of molecular biology in the study of these parasites and some species previously considered synonymous came to be regarded as valid and others were described. The use of molecular techniques allowed to distinguish differences in the structure of some sporozoites components within the oocysts as enzymes and nucleic acids, which allowed the separation of different genotypes C. parvum, the most pathogenic species and increase the frequency in human infections.

Until now, it is recognized 15 species of Cryptosporidium (Fayer, 2004), with several subtypes (Xiao, 2010), C. andersoni, C. baileyi, C. canis, C. felis, C. galli, C. hominis, C. meleagridis, C. molnari, C. muris, C. nasorum, C. parvum, C. saurophilum, C. serpentis, C. varanii and C. wrairi. These are recognized to date seven species that can cause diarrheal disease in human, $C$. hominis, C. paroum, C. meleagridis, C. felis, C. canis, C. suis and C. muris; C. parvum and C. hominis are responsible... (Cacciò et al., 2005; Bouzid et al., 2008).

Although Cryptosporidium species are described since the early 20th century, it was only at the end of that century which the protozoan was recognized as a pathogen of cattle and horses, pets and wildlife, and a problem for public health. It was recognized that drinking or 
recreational water contaminated is a major source of transmission, following the discovery of resistant oocyst stage in the environment that transmits the infection of host to host via contaminated feces. The development of molecular tools to identify morphologically indistinguishable species allowed the researchers to define relationships between parasite species, potential hosts and routes of transmission (Fayer, 2004).

The diversity of reservoirs and the means of Cryptosporidium spp. transmission associated with their ability to survive in the environment generate an extensive network of transmission and sources of infection for humans and animals (Furtado et al., 1998). The individual's susceptibility to infection as well as the severity and duration of that vary considerably from individual to individual, depending on immune health, nutritional status and previous exposure. Similarly, an acquired immune response may limit the duration and severity of the infection. The period between the ingestion of oocysts and the development of symptoms is 7-10 days, ranging from 5-28 days (Fayer \& Ungar, 1986). Infected hosts may excrete between $10^{9}$ and $10^{10}$ oocysts per gram of feces, with the intake of 30 oocysts may result in human infections, which after the third day of exposure to the agent can cause profuse diarrhea with severe dehydration, intense abdominal pain, nausea, vomiting and even fever (Smith \& Rose, 1998).

The rapid lifetime, the auto-infective cycles of Cryptosporidium can lead to large numbers of infected cells in the small intestine, resulting in secondary infection of the duodenum and large intestine. In immunocompromised patients the parasite has been found in the stomach, pancreatic and bile duct, and respiratory tract (Butler \& Mayfield, 1996).

In the immunocompetent patients, the disease is self-limiting, the symptoms are often sudden with diarrhea over about 10-14 days, although there are cases described as long as three to five weeks. The symptoms disappear spontaneously and within a few months get the parasitological cure. The excretion of oocysts in the feces is intermittent and usually longer than the symptomatic phase of disease (Andrade Neto \& Assef, 1996).

In immunocompromised individuals, infection is chronic and the severity and persistent diarrhea are greater than in immunocompetent individuals, it can persist indefinitely and evolve into intense dehydration and death. There is no data to indicate that immunocompromised individuals are more susceptible to infection than immunocompetent individuals. However, those with compromised immune systems are more severely affected by cryptosporidiosis (Butler \& Mayfield, 1996).

The control of cryptosporidiosis is often limited by the high resistance of the oocysts to disinfectants commonly used, such as ammonia, sodium hypochlorite and chlorine. The absence of an effective treatment to combat infection increases the magnitude and enhances the importance of preventing cryptosporidiosis. The oocysts control in public water supplies, in the face of their resistance to conventional treatment is a concern worldwide, and numerous studies have been developed for this purpose (Assavasilavasukul et al., 2008; Brown \& Emelko, 2009). 
The small size of the oocysts, as well as apparently existing flexibility facilitate the passage of Cryptosporidium in filtration processes performed during the water treatment for supply. Rose (1990) report that $57 \%$ of oocysts were able to cross a membrane filter with a $3 \mu \mathrm{m}$ pore diameter. On the other hand, in analysis of washing water from rapid filters was observed high concentrations $(2,906$ to 24,306 oocysts/L), indicating that the filters were effective in removing oocysts (Rose, 1990). Sterling (1990) analyzing the number of oocysts detected in the raw water and in the same post-treatment, noted a removal efficiency of $91 \%$. Filtration without prior coagulation achieved oocyst removal of $54.6 \%$ and $91.4 \%$ from effluent and surface water (rivers), respectively. Moreover, oocysts were detected in conventional water after treatment (coagulation, sedimentation, filtration and chlorination) and removal was estimated at 93.3\%, with no operational problem identified (Muller, 1999).

Further studies are being conducted to improve the treatment processes, optimizing filtration processes, operating conditions, including the coagulant dosage, mixing and monitoring of filters (Rose, 1990; Brown \& Emelko, 2009). Problems such as coagulant dosages, inadequate processes of mixing, inadequate monitoring of filters, turbidity, using saturated filters, among others were analyzed in Pennsylvania by Consonery et al. (1997), with optimization of processes, positive samples were reduced from $35 \%$ to values lower than $5 \%$.

Oocysts and other microorganisms that are not effectively removed by filtration should therefore be inactivated by the disinfection process. However, the Cryptosporidium spp. oocysts have shown considerably resistant to the effects of most commercial disinfectants (Muller, 1999). Although chlorine and related components could reduce the ability of the oocyst to infect, the concentration relatively high and long exposure time necessary limit the practical implementation. For the majority of chemicals studied, effective concentrations are unusual for disinfection outside the laboratory, and high concentrations to reduce infectivity are expensive and toxic. Exposure to ammonia in liquid or gaseous phase and hydrogen peroxide has been effective in reducing and eliminating oocysts (Fayer, 1997).

Campbell et al. (1982) demonstrated that Cryptosporidium is able to remain viable, when exposed to sodium hypochlorite and chlorine. Thus, disinfection by chlorine in the concentrations commonly used in conventional water treatment is not effective in the inactivation of the parasite. Due to high doses and long period of exposure required for disinfecting, ultraviolet radiation is not considered a viable practice for the disinfection of oocysts (Fayer, 1997). Ozone has been appointed by some authors as one of the most important chemical disinfectants in inactivating oocysts (Fayer, 1997). Peeters et al. (1989) and Korich et al. (1990) reported that at a concentration of disinfectant (TC) from $3.5-10$ $\mathrm{mg} / \mathrm{min} / \mathrm{L}$, 99 to $99.99 \%$ of oocysts were inactivated. Laboratory studies have been conducted to assess the limits of oocysts survival exposed to heat, cold, desiccation and ultraviolet radiation. As documented in the scientific literature, temperatures above $64.2{ }^{\circ} \mathrm{C}$ for 5 minutes and $72.4^{\circ} \mathrm{C}$ for 1 minute, inactivate oocysts. On the other hand, oocysts suspended in water or milk remain infective when exposed to $71.7{ }^{\circ} \mathrm{C}$ for 5,10 and 15 
seconds. The oocysts can resist freezing at $-20^{\circ} \mathrm{C}$ for long periods, but do not survive to -70 ${ }^{\circ} \mathrm{C}$ (Butler \& Mayfield, 1996; Fayer, 1997).

\subsection{Giardia spp. and giardiosis}

The genus Giardia spp. includes flagellate parasites presented in small intestine of mammals, birds, reptiles and amphibians, and possibly the first human intestinal protozoan to be known. The first description of the trophozoite has been attributed to Anton van Leeuwenhoek (1681), who noted Giardia trophozoites in their own feces, but it was Larnbl in 1859, who described it in more detail. The genus was created by Kunstler (1882) when observing a flagellate present in the intestines of tadpoles of anuran amphibians (Neves, 2005).

Giardia duodenalis (syn. G. lamblia, G. intestinalis) causes giardiosis, gastroenteritis caused by unicellular protozoan. This protozoan is probably the most widespread cause of diarrhea with 200 million of symptomatic individuals in the world. The majority of infections by G. duodenalis are asymptomatic, and the prevalence is $2-5 \%$ in industrialized countries and 20$30 \%$ in developing countries. Regarding the symptoms may be asymptomatic or present a wide spectrum of symptoms, from self-limiting enteritis to chronic conditions with debilitating diarrhea, steatorrhea and weight loss (Rey, 2001).

Giardia and giardiosis have been extensively studied and, despite the efforts, many fundamental questions still remain unanswered. The own taxonomy is still controversial and the determination of Giardia species has been made considering the host of origin and morphological characteristics. According to some authors, consider the host of origin is not a valid criterion, once, by the DNA analysis, Giardia species from different hosts are similar, while those from the same host can be quite different (Neves, 2005). The difficulty in determining accurately the species of isolated Giardia from different hosts has been a limiting factor for the establishment of the zoonotic potential of giardiosis and to clarify the possibility of the existence of animals that can participate as reservoirs of Giardia spp.

Currently, the classification has been adopted for G. duodenalis is the categorization of the species in 7 genotypes or "assemblages": A, B, C, D, E, F and G. Only the A and B genotypes have been detected in humans, but both can infect other mammals, i.e, they have potential zoonotic (Bouzid et al., 2008). Subgroup AI is a mixture of isolated human and animals, since the sub-group AII is strictly isolated from humans. The genotype B comprises two subgroups III and IV and this last one is probably specific human (Thompson, 2004). The other five assemblages (CG) comprise species G. duodenalis restricted to host animals. Molecular analysis of $G$ duodenalis isolates and other Giardia species conclude that the first is a complex of species and shows the need for a revision in the taxonomy of Giardia (Bertrand \& Schwartzbrod, 2007).

The cysts are released for an extended period and in large numbers $\left(1.4 \times 10^{10}\right.$ daily) in the feces of humans and certain animals. Can survive for several months in cold water, are relatively resistant to chlorination and ultraviolet light. The boiling is very effective in 
destroying the cysts, but some may resist freezing for a few days. The infection can be caused by low doses of up to 10 cysts, can occur by direct contact, very common among children in day care center and through ingestion of contaminated food or water (Ortega et al., 1997).

Due to several reasons, nowadays giardiosis is considered a reemerging parasitic. The first of these reasons relates to the large number of diarrhea outbreaks in day care centers. In developed countries, the increasing use of these institutions is one reason for the reemergence of the disease. Another reason pointed out as a cause of re-emergence of this disease relates to high rates of Giardia infection in domestic animals (Thompson, 2000).

The filtration processes are important barrier for removal of cysts in the water treatment. The main concern in water treatment plants for cysts removal should focus on the filtration processes, as well as optimizing operations and improvements in processes for cysts removal (Plutzer et al., 2010).

Disinfection with chlorine and derivatives is an important barrier to waterborne pathogens, however they are less effective against Giardia cysts (Khalifa et al., 2001). As previously mentioned, chlorine can cause the inactivation of cysts, but requires concentration and contact time high (Medema et al., 2006). Ozone is the powerful agent against protozoa, however the contact time required is still high (Haas \& Kaymak, 2003). Furthermore, chemical disinfecting agents cannot be used at very high doses due to the formation of disinfection byproducts formed by the reaction with organic matter of water, such as trihalomethanes (Von Gunten, 2003).

There is also the risk of post-contamination (Karanis et al., 2007) when the water distribution system or water reservoirs are contaminated. This post-contamination can occur because of leakage of contaminants along the distribution system, on distribution reservoirs opened or due to inadequate disinfection after construction or repair in the network. Improper connections can inject water sources contaminated with domestic sewage on the distribution network. Public or domestic water tanks can be contaminated due to animals' access (Robertson et al., 2009).

Biofilms formation in the pipeline distribution network can also contribute as a potential source for water contamination by Giardia cysts, serving as a means of accumulation during periods of slow flow (Helmi et al., 2008).

\subsection{Moringa oleifera Lam}

Moringa oleifera (moringa) is a tropical plant belonging to the family Moringaceae (Katayon et al., 2006), a single family of shrubs with 14 known species. Moringa is native of India but is now found throughout the tropics (Bhatia et al., 2007). Moringa seeds contain a non-toxic natural organic polymer which is an active agent with excellent activity and coagulating properties. The tree is generally known in the developing world as a vegetable, a medicinal plant, and a source of vegetable oil (Katayon et al., 2006). Its leaves, flowers, fruits, and roots 
are used locally as food ingredients. The medicinal and therapeutic properties of moringa have led to its utilization as a cure for different ailments and diseases, physiological disorders, and in Eastern allopathic medicine (Akhtar et al., 2007). Additionally, the coagulant is obtained at extremely low or zero net cost (Ghebremichael et al., 2005).

If moringa is proven to be active, safe, and inexpensive, it is possible to use it widely for drinking water and wastewater treatment. Besides, moringa may yet have financial advantages bringing more economic benefits for the developing countries (Okuda et al., 1999).

The moringa seed has a protein that when solubilized in water is able to promote coagulation and flocculation of compounds that cause color and turbidity in highly turbid water. Several studies have also shown their effective antimicrobial and antifungal capacity, thereby contributing to good water quality at low cost (Chuang et al., 2007; Coelho et al., 2009). Several studies have shown the effectiveness of moringa on color, turbidity and other compounds removal present in the water.

Moringa has been found to be effective as a natural coagulant for high turbidity water in previous studies (Okuda et al., 2001). This was verified in a study by Nishi (2011). The authors obtained values of color and turbidity removal over $90 \%$ when the water to be treated showed high values of initial turbidity, between 350 and 450 NTU. A moringa concentration of $150 \mathrm{mg} / \mathrm{L}$ would have been sufficient to achieve this level of removal. The coagulant derived from moringa seeds, as it contains a certain amount of organic matter, can give color and turbidity to the treated water.

An important point to be considered when using moringa as a coagulant is related to the $\mathrm{pH}$ of the water to be treated. For chemical coagulants, water $\mathrm{pH}$ adjustment is necessary for the flakes to be properly formed. In the case of the moringa, there is no need for this adjustment, and this parameter is not changed after treatment, as evidenced by Vieira et al. (2010). Moringa is an efficient coagulant in a wide $\mathrm{pH}$ range (6-8), which is an advantage compared with other coagulants, as the $\mathrm{pH}$ adjustment step can be eliminated in the coagulation/flocculation processes.

\section{Materials and methods}

\subsection{Water samples}

Surface water used in the tests was collected in the river basin Pirapó, which supplies the Maringa city, Paraná, Brazil. Samples of the water with high and low turbidity were mixed in order to obtain different initial turbidity in the range 50 - 450 NTU. Prepared samples were artificially contaminated with $10^{6}$ cysts/L for Giardia spp. and $10^{6}$ oocysts of Cryptosporidium spp. obtained from the positive control (suspension of cysts and oocysts) present in the commercial kit Merifluor ${ }^{\circledR}$ (Meridian Bioscience, Cincinnati, OH, USA).

After sample preparation, these were submitted to processes of (1) coagulation/flocculation with moringa seeds (CFM), (2) microfiltration (MF) and (3) combined coagulation/flocculation with moringa seeds followed by microfiltration (CFM-MF). 


\subsection{Coagulation/flocculation with moringa (CFM)}

The coagulant solution of moringa was prepared and used on the same day. $1 \mathrm{~g}$ of mature Moringa oleifera Lam seeds, from the Federal University of Sergipe (UFS), manually removed from the dried pods and shelled were crushed in a blender with $100 \mathrm{~mL}$ of distilled water. After grinding, the solution was stirred for $30 \mathrm{~min}$ and vacuum filtered, obtaining a solution $1 \%$ of moringa seeds (moringa concentration in solution $=10.000 \mathrm{mg} / \mathrm{L}$ ) (Cardoso et al., 2008, Madrona et al., 2010). From this solution, it was used 12 concentration levels ranging from: 25 to $350 \mathrm{mg} / \mathrm{L}$ (Table 1 ).

\begin{tabular}{ccccccccccccc}
\hline $\begin{array}{c}\text { Initial turbidity of water } \\
\text { samples (NTU) }\end{array}$ & 50 & 150 & 250 & 350 & 450 & & & & & & & \\
$\begin{array}{c}\text { Moringa solution } \\
\text { concentration (mg/L) }\end{array}$ & 25 & 50 & 75 & 100 & 125 & 150 & 175 & 200 & 225 & 250 & 275 & 300 \\
\hline
\end{tabular}

Table 1. Initial turbidity and e concentrations of moringa solution used in experiments.

CFM tests were conducted in a Jar-Test equipment, Nova Ética - Model 218 LDB in six buckets, with rotation regulator of mixing rods. The experimental conditions for the CFM process were: rapid mixing gradient $(100 \mathrm{rpm})$, rapid mixing time $(3 \mathrm{~min})$, slow mixing gradient $(10 \mathrm{rpm})$, slow mixing time $(15 \mathrm{~min})$ and settling time $(60 \mathrm{~min}$ ) (Cardoso et al., 2008, Madrona et al., 2010).

In this process, the measured parameters in experiments were color, turbidity, $\mathrm{pH}$, Giardia spp. and Cryptosporidium spp. removal.

\subsection{Microfiltration process $(\mathrm{MF})$ and coagulation/flocculation/ microfiltration sequence (CFM/MF)}

The membrane filtration tests were performed on a microfiltration bench unit (PAMMembranas Seletivas ${ }^{\circledR}$ ) (Figure 1). This module is made of stainless steel, with polymeric membrane (1). The system is composed by manometers (2) and flow meter (3) to control the transmembrane pressure and flow rate, feed tank (4) with volume capacity of 5 liters. The permeate output (5) was collected with valve opening (6) and the return of the concentrate to the feed tank was conducted through the pipe (7).

The MF membrane employed had form of hollow fibers made up of poly (imide), with 0.40 $\mu \mathrm{m}$ pore diameter, fiber external diameter between 0.8 and $0.9 \mathrm{~mm}$, fibers with external selective layer. The filtration is cross flow and the pressure used was 1.0 bar. In order to have uniformity in the tests set up the feed initial volume of 5 liters and assay time of 60 minutes.

In this part of the study, MF without pretreatment and coagulation/flocculation/ microfiltration sequence with moringa (MF-CFM) were performed. These processes were performed to observe if MF with pre-treatment (coagulation/flocculation with moringa) showed differences between the MF processes without pre-treatment. The membrane processes, in addition to analysis of Giardia spp., Cryptosporidium spp., color and turbidity removal, it was also measured permeate flux and membrane fouling. 


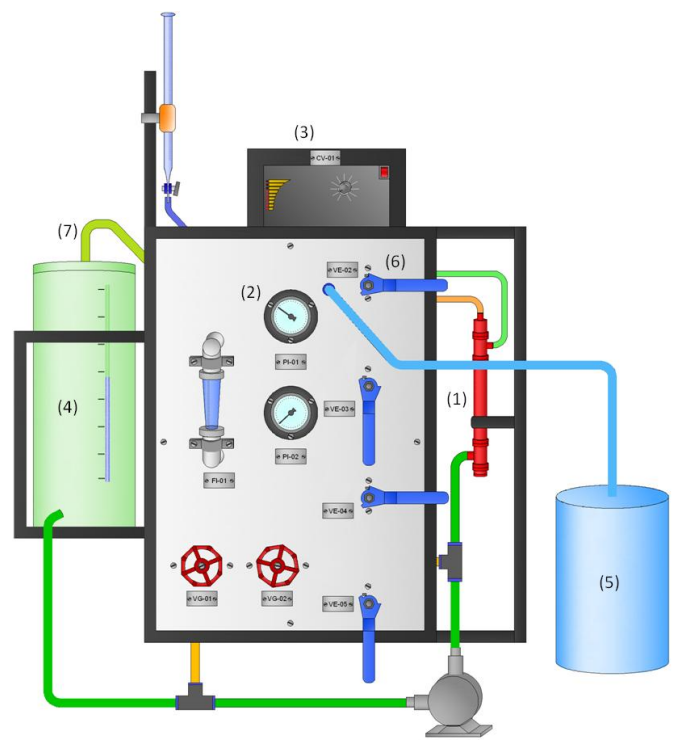

Figure 1. Scheme of front view of MF module.

\subsubsection{Evaluation of permeate flux and fouling percentage of membranes for $M F$ and CFM-} MF processes

The membranes were first compacted and were then stabilized with deionized water until achieving a steady permeate flux. Permeate samples were collected at predetermined times, by known time intervals, and analytical balance were used to measure the permeate flow rate indirectly based on weight increase, according to the Equation (1).

$$
f=\frac{m}{\rho \cdot \Delta t \cdot A_{m}}
$$

where $\mathrm{f}$ is the permeate flux, $\mathrm{m}$ is permeate mass $(\mathrm{g}), \mathrm{Q}$ is the water density $\left(25^{\circ} \mathrm{C}\right), \Delta \mathrm{t}$ is the time interval during which the sample was collected (s) and $A_{m}$ is the surface area.

The permeate samples were collected at shorter time intervals at the beginning of filtration, such intervals, increased subsequently to determine the curve of permeate flux versus time. The membrane filtration processes were performed using raw water (RW) without pretreatment and after coagulation/flocculation with moringa (CFM).

The removal efficiency for each parameter analyzed using different treatment processes was calculated from Equation (2), where $\mathrm{C}_{\mathrm{i}}$ and $\mathrm{C}_{\mathrm{f}}$ are the initial and final concentrations, respectively, to each parameters:

$$
\% \text { removal efficiency }=\left(\frac{C_{i}-C_{f}}{C_{i}}\right) x 100
$$


The water flux of deionized water (DW) were determined before each experiment ( $\mathrm{J}_{\text {initial }}$ ) and after the MF of RW and CFM solutions (Jfinal) for determining the fouling of the membrane. The percentage of fouling (\% F) was calculated according to Equation (3), proposed by Balakrishnan et al. (2001), using stable flow values, which assume that the flow tends to constant values. This \%F represents a reduction of deionized water flow after tests with contaminated water. In Equation (3), F\% is the percentage of fouling, $\mathrm{J}_{\mathrm{i}}$ is the initial flow of water obtained in the first filtration with deionized water and $\mathrm{J}_{\mathrm{f}}$ is the final flow of water obtained with the filtration of deionized water after filtration of surface water.

$$
\% F=\frac{\left(J_{i}-J_{f}\right)}{J_{i}} x 100
$$

\subsection{Parameters evaluated}

The parameters evaluated were apparent color, turbidity, $\mathrm{pH}$, Giardia spp. e Cryptosporidium spp. These parameters were analyzed according to the procedures described below.

\subsubsection{Apparent color}

The color was measured on a spectrophotometer HACH DR 2010, method 8025, program 120, wavelength of $455 \mathrm{~nm}$, by visual comparison with platinum-cobalt standard, according to the procedure recommended by the Standard Methods (APHA, 1995). The result of color was given in $\mathrm{uH}=$ Hazen $\mathrm{unit}(\mathrm{mgPt}-\mathrm{Co} / \mathrm{L})$.

\subsubsection{Turbidity}

The turbidity was determined in Turbidimeter portable HACH - Model 2100P, according to the procedure recommended by the Standard Methods (APHA, 1995). The result of turbidity was expressed in NTU (Nephelometric Turbidity Units).

\subsubsection{Giardia spp. e Cryptosporidium spp. analisys}

The treated samples were evaluated for the presence of Giardia spp. e Cryptosporidium spp. by membrane-filtration technique, with mechanical extraction and elution (Aldom \& Chagla 1995; Dawson et al. 1993; Franco et al., 2001) (Figure 2). This technique was performed as follows:

1) Filtration in cellulose acetate membrane (Millipore ${ }^{\circledR}$ ), with $47 \mathrm{~mm}$ pore diameter and 1.2 $\mu \mathrm{m}$ porosity, 2) mechanical extraction of the material retained on the membrane with the aid of plastic spatulas by alternating washes of the membrane surface during 10 minutes in a Petri dish with a solution of elution Tween $801 \%$,3) Repeat of procedure (2) to extract the greatest possible amount of material retained; 4) the material was centrifuged at $600 \mathrm{x} g$ for 
15 minutes. The supernatant was discarded with the aid of glass pipettes until the volume of $3 \mathrm{ml}$ and the sediment was resuspended in distilled water by supplementing $15 \mathrm{ml}$ of centrifuge tube and then centrifuged again at $600 \mathrm{xg}$ for 15 minutes, 5) The supernatant was discarded to a volume of $1 \mathrm{ml}$ of centrifuge tube and the sediment was resuspended in this volume.

Of the sediment resuspended in $1 \mathrm{ml}$ of distilled water, $5 \mu \mathrm{l}$ were used for the direct immunofluorescence technique, using the Merifluor commercial kit (Meridian Bioscience,

Cincinnati, OH, USA). Simultaneously, a confirmatory test was performed with inclusion of the fluorogenic vital stain DAPI $(4 \$, 6 \$$-diamidine-2-phenylindole; Sigma Chemicals Co., St Louis, MO, USA) to reveal the morphological characters (nucleus, axoneme and suture) (Cantusio Neto \& Franco, 2004). To read the preparations, an Olympus BX51 epifluorescent microscope was used (with excitation filter: $450-490 \mathrm{~nm}$ and emission filter: $520 \mathrm{~nm}$ for the Merifluor; excitation filter: $365-400 \mathrm{~nm}$ and emission filter: $395 \mathrm{~nm}$ for the DAPI). The numbers of oocysts and cysts per litre in the positive samples were estimated by the following calculation (EPA, 1999; Cantusio Neto \& Franco, 2004):

$$
X=\left(\frac{\mathrm{n}^{\circ} \text { oocysts } \times 10^{6} \times \text { pellet volume }(1 \mathrm{~mL})}{\text { volume used/blade } \times \text { sample volume }(\mathrm{mL})}\right)
$$

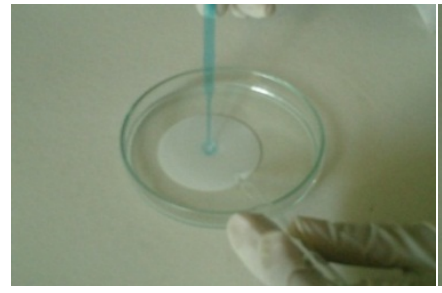

(a)

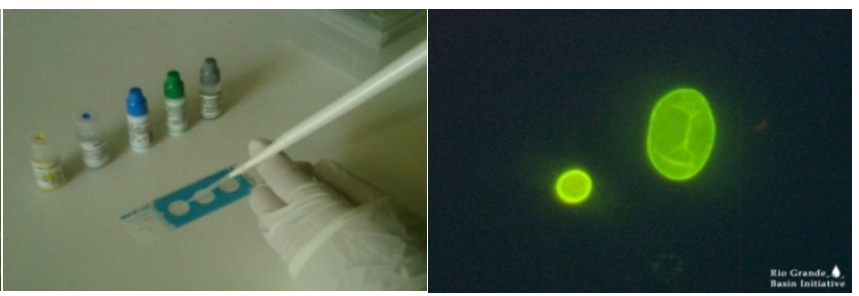

(b) (c)

Figure 2. Membrane-filtration technique, with mechanical extraction and elution (a), analysis by direct immunofluorescence with Merifluor Kit (b) and Cryptosporidium spp. (left) e Giardia spp. (right) visualized in immunofluorescence.

\section{Results}

The following are the results obtained in the processes of coagulation/flocculation with moringa (CFM), microfiltration (MF) and coagulation/flocculation/microfiltration sequence with moringa (CFM-MF) for protozoan parasites, color, and turbidity removal and $\mathrm{pH}$ values of the of treated water samples.

\subsection{Results obtained in coagulation/flocculation process with moringa (CFM)}

The initial characteristics of water samples used in the study are presented in Table 2. 


\begin{tabular}{ccc}
\hline Turbidity (NTU) & Color $(\mathrm{uH})$ & $\mathrm{pH}$ \\
\hline 50 & 350 & 7.80 \\
150 & 902 & 7.81 \\
250 & 1000 & 7.50 \\
350 & 1849 & 7.64 \\
450 & 1885 & 7.70 \\
\hline
\end{tabular}

Table 2. Water sample parameters before treatment processes.

Table 3 presents the results of turbidity, color and parasitic protozoa removal efficiency and $\mathrm{pH}$ values of water samples after coagulation/flocculation with moringa.

\begin{tabular}{|c|c|c|c|c|c|c|c|c|c|c|c|c|c|}
\hline \multirow[b]{2}{*}{$\begin{array}{l}\text { Initial turbidity } \\
\text { (NTU) }\end{array}$} & \multirow[b]{2}{*}{$\begin{array}{l}\text { Removal efficiency } \\
(\%)\end{array}$} & \multicolumn{12}{|c|}{ Moringa solution concentration $1 \%(\mathrm{mg} / \mathrm{L})$} \\
\hline & & 25 & 50 & 75 & 100 & 125 & 150 & 175 & 200 & 225 & 250 & 275 & 300 \\
\hline \multirow[t]{5}{*}{50} & Turbidity & 27.7 & 23.0 & 20.7 & 33.4 & 33.2 & 35.6 & 44.4 & 45.6 & 41.6 & 27.6 & 10.0 & 3.0 \\
\hline & Color & 0.35 & 0.11 & 1.65 & 3.07 & 4.00 & 6.60 & 22.8 & 27.6 & 30.0 & 26.0 & 15.4 & 16.7 \\
\hline & Giardia & 6.00 & 42.3 & 38.4 & 69.2 & 84.6 & 76.9 & 82.0 & 80.0 & 80.0 & 76.9 & 85.0 & 69.0 \\
\hline & Cryptosporidium & 76.0 & 91.0 & 90.0 & 98.0 & 93.0 & 91.0 & 98.0 & 86.0 & 91.0 & 88.0 & 89.0 & 83.0 \\
\hline & $\mathrm{pH}$ & 7.90 & 8.20 & 8.10 & 8.20 & 8.20 & 8.10 & 8.20 & 7.90 & 8.00 & 8.10 & 8.00 & 7.90 \\
\hline \multirow[t]{5}{*}{150} & Turbidity & 42.0 & 52.4 & 69.8 & 71.0 & 74.0 & 75.8 & 67.7 & 65.3 & 69.0 & 73.6 & 76.0 & 72.0 \\
\hline & Color & 10.0 & 47.5 & 67.0 & 68.8 & 70.8 & 73.5 & 73.5 & 71.4 & 65.0 & 63.4 & 66.4 & 61.6 \\
\hline & Giardia s] & 74.0 & 97.0 & 85.0 & 98.0 & 94.0 & 98.0 & 98.0 & 98.0 & 97.0 & 97.0 & 91.0 & 82.0 \\
\hline & Crypto & 42.0 & 50.0 & 77.0 & 81.0 & 81.0 & 92.0 & 92.0 & 92.0 & 85.0 & 92.0 & 81.0 & 58.0 \\
\hline & $\mathrm{pH}$ & 7.93 & 7.96 & 7.85 & 7.74 & 7.8 & 7.76 & 7.70 & 7.74 & 7.81 & 7.74 & 7.72 & 7.68 \\
\hline \multirow[t]{5}{*}{250} & Turbidity & 68.9 & 74.8 & 80.6 & 93.4 & 90.1 & 94.4 & 93.9 & 94.2 & 90.9 & 94.6 & 91.8 & 92.7 \\
\hline & Color & 21.8 & 46.5 & 46.2 & 68.4 & 64.4 & 80.7 & 79.0 & 81.3 & 78.0 & 77.8 & 88.4 & 81.6 \\
\hline & Giardia s & 80.0 & 65.0 & 65.0 & 80.0 & 80.0 & 95.0 & 95.0 & 95.0 & 95.0 & 90.0 & 92.5 & 90.0 \\
\hline & Crypto & 67.0 & 61.0 & 75.0 & 74.0 & 86.0 & 96.0 & 95.0 & 92.0 & 94.0 & 90.0 & 87.0 & 78.0 \\
\hline & $\mathrm{pH}$ & 7.60 & 7.70 & 7.80 & 7.80 & 7.60 & 7.60 & 7.70 & 7.80 & 7.80 & 7.80 & 7.70 & 7.80 \\
\hline \multirow[t]{5}{*}{350} & Turbid & 49.4 & 62.8 & 70.8 & 75.0 & 82.0 & 90.0 & 93.7 & 95.0 & 96.0 & 95.8 & 96.4 & 92.5 \\
\hline & Color & 47.0 & 82.3 & 76.4 & 94.0 & 94.0 & 88.2 & 97.0 & 97.0 & 94.0 & 88.2 & 94.0 & 94.0 \\
\hline & Giardia spp. & 47.0 & 82.3 & 76.4 & 94.0 & 94.0 & 88.2 & 97.0 & 97.0 & 94.0 & 88.2 & 94.0 & 94.0 \\
\hline & Cryptos & 22.0 & 81.0 & 68.0 & 95.0 & 86.0 & 81.0 & 97.0 & 96.0 & 92.0 & 86.0 & 96.0 & 92.0 \\
\hline & $\mathrm{pH}$ & 7.78 & 7.87 & 7.75 & 7.77 & 7.81 & 7.74 & 7.82 & 7.75 & 7.73 & 7.76 & 7.73 & 7.78 \\
\hline \multirow[t]{5}{*}{450} & Turbidity & 63.0 & 61.0 & 75.0 & 79.9 & 92 & 94.0 & 97.2 & 97.4 & 97.2 & 97.0 & 96.7 & 94.7 \\
\hline & Color & 39.0 & 47.8 & 61.6 & 68.5 & 88.3 & 91.5 & 96.1 & 96.1 & 96.4 & 96.0 & 95.6 & 92.8 \\
\hline & Giardia spp. & 63.0 & 92.0 & 96.0 & 96.0 & 92 & 96.0 & 90.0 & 97.0 & 94.0 & 97.0 & 93.0 & 89.2 \\
\hline & Cryptosporidium & 45.0 & 51.0 & 94.0 & 85.0 & 80 & 94.0 & 86.0 & 93.0 & 95.0 & 98.0 & 90.0 & 76.0 \\
\hline & $\mathrm{pH}$ & 7.80 & 7.70 & 7.60 & 7.60 & 7.60 & 7.60 & 7.60 & 7.60 & 7.60 & 7.60 & 7.50 & 7.60 \\
\hline
\end{tabular}

Table 3. Percentage removal efficiency of turbidity, color, Giardia e Cryptosporidium and $\mathrm{pH}$ values after coagulation/flocullation process with moringa.

Using moringa as coagulant, turbidity ramoval was in the range of $3-97,4 \%$. The lower removal efficiencies were in the range of $3-45,6 \%$ for water with low initial turbidity (50 NTU), removal below $90 \%$ were observed for water with turbidity 250, 350 e 450 NTU. The 
decrease in efficiency of turbidity removal in water with initial turbidity 50 NTU, after the moringa addition, can be explained by an increase in organic load. This is justifiable, considering moringa is an oilseed rich in organic substances such as oil, protein, fat, vitamins, etc.. This parameter increase in color and turbidity in water treated with moringa is observed in other studies, especially when the water has initial color and turbidity relatively low (Ramos, 2005).

Nkurunziza et al. (2009), using solution of moringa seeds 3\%, prepared in saline solution, in water from rivers of province Rwanda, observed removal efficiency of $83.2 \%$ in the samples with turbidity of 50 NTU and higher removals ( $99.8 \%$ ) in water with turbidity of 450 NTU. The best concentrations found in this study were $150 \mathrm{mg} / \mathrm{L}$ for $50 \mathrm{NTU}$ and 125mg/L for other levels of turbidity tested by researchers. The results of turbidity removal for water with low initial turbidity (50 NTU) were higher than those obtained in this study $(45.6 \%)$ and for water with high initial turbidity (450 NTU) were similar $(97.4 \%)$. The differences may be due to the way of moringa solution preparation by extracting aqueous or saline, and different concentrations used of the moringa stock solution ( $1 \%$ in this study). In both studies, it was noted that the coagulating property of the moringa is shown more effectively in water with high initial turbidity, in agreement with published studies (Ndabigengesere et al., 1995; Madrona et al, 2010).

Ndabigengesere et al. (1995) using solution of moringa seeds $5 \%$ on synthetic turbid water (kaolin) with initial turbidity of $426 \mathrm{NTU}$, obtained removal of $80-90 \%$ and reached the optimum concentration of $500 \mathrm{mg} / \mathrm{L}$ coagulant solution. This concentration is higher than optimal concentration of $450 \mathrm{NTU}$ water obtained in this study, which was $275 \mathrm{mg} / \mathrm{L}$. This difference between the optimal concentrations of the moringa solution may have occurred due to the water used in the study. Ndabigengesere et al. (1995) used synthetic water prepared with kaolin and the present study used surface water. Cardoso et al. (2008), however, used similar conditions to the present study, obtained turbidity removal of $91.4 \%$ in surface water from the river Pirapó with 247 NTU, with aqueous moringa, removal efficiency with a value close to that observed in this study $(96 \%$ rof turbidity removal for water with initial turbidity of 250 NTU). Thus, the similarities or differences between the removal efficiencies of turbidity and optimal concentrations can be explained by the different types of water samples used by the works (raw water, artificial water), as well as the method of moringa solution preparation (salt extraction, aqueous) concentrations evaluated, seed quality, among other factors.

With respect to color, removal ranged from 0.11 to $30 \%$ for water with initial turbidity of 50 NTU, high removals in this sample were within the concentration range 175-250 mg/L. Water with higher initial turbidity (150-450 NTU), the removal efficiency varied from 10 to $97 \%$, with the major removals from the concentration of $150 \mathrm{mg} / \mathrm{L}$ of the coagulant. It is observed that the color removal by Moringa is similar to its behavior with respect to turbidity, the lowest values of the color parameter are obtained in waters with high initial turbidity, which agrees with literature data (Cardoso et al., 2008; Nkurunziza et al., 2009; Madrona et al., 2010). For pH values of water samples after the coagulation process with different concentrations of moringa, it was observed that the $\mathrm{pH}$ is maintained, on average, 
7.6, ranging from about $10 \%$. There was little variation between samples regardless of the amount of moringa solution added, which consists of one of the advantages of moringa as a coagulating agent, i.e., its addition does not significantly alter the $\mathrm{pH}$ of water (Ndabigengesere et al., 1995; Nkurunziza et al., 2009), unlike treatment with aluminum sulfate in which it is necessary to adjust the $\mathrm{pH}$ of the water to improve its coagulating action, increasing the amount and cost of chemicals for water treatment.

Regarding the removal of Giardia cysts and Cryptosporidium oocysts were observed similar behavior between the samples. The best removal of both Giardia and Cryptosporidium occurred since the concentration of $150 \mathrm{mg} / \mathrm{L}$ of moringa solution for all treated water samples, with an average removal efficiency of 93\% (1.2 log removal) and 90\% (1 log removal), respectively. In the literature no studies were found regarding the removal of these protozoan parasites using Moringa as a coagulating agent. The obtained high removal can be explained by the moringa coagulant action, based on the presence of cationic proteins in seeds. These proteins are heavily loaded cationic dimers with molecular weight of about $13 \mathrm{kDa}$, and the charge neutralization and adsorption the main mechanisms of moringa coagulation (Ndabigengesere et al., 1995). As the calculated zeta potential of Giardia and Cryptosporidium oocysts in water at neutral $\mathrm{pH}$ are, on average, -17 and $-38 \mathrm{mV}$, respectively (Hsu \& Huang, 2002), the mechanism for charge neutralization of proteins natural coagulant could act in the removal of protozoan parasites.

The removal of protozoan parasites obtained in this study is close to the results of other studies, using chemical coagulants such as aluminum sulfate and ferric chloride, for these microorganisms removal of these microorganisms (Bustamante et al 2001; Xagoraraki \& Harrington, 2004), and also charge neutralization the main mechanism of coagulation using aluminum sulfate in that frame. Brown \& Emelko (2009) analyzed other natural coagulant, chitosan, for the removal of Cryptosporidium parvum in pilot scale treatment with artificial water (kaolin), using concentrations of $0.1,0.5$ and $1.0 \mathrm{mg} / \mathrm{L}$ of chitosan solution. The authors achieved excellent reductions in turbidity, but not observed good results in $C$. parvum removal with average less than $10 \%$. A possible explanation for this difference, since the chitosan is a cationic polymer, also is the possibility that during the coagulation /flocculation process, the oocysts are also removed by engagement with the flakes, and this is another mechanism participating in the removal of the protozoan (Bustamante et al., 2001). Whereas the flakes formed depending on the characteristics of particles in the water, it can be said that the removal of microorganism will also depend on these characteristics, since Brown \& Emelko (2009) used artificial water and in this study it was used natural raw water.

\subsection{Results obtained in microfiltration process (MF) and coagulation/flocculation/microfiltration sequence (CFM-MF)}

The results obtained in the processes of microfiltration (MF) and coagulation/flocculation with moringa followed by microfiltration (CFM-MF) are presented below. These results are presented together to show if the pretreatment (coagulation/flocculation with moringa) had 
differences in relation to the MF process without pretreatment. The removal efficiencies and the $\mathrm{pH}$ of the water treated by the MF and CFM-MF processes are presented in Table 4.

\begin{tabular}{cccccc}
\hline & & \multicolumn{4}{c}{ Initial turbidity (NTU) } \\
\cline { 3 - 6 } Treatment process & Removal efficiency (\%) & 150 & 250 & 350 & 450 \\
\hline \multirow{3}{*}{ MF } & Turbidity & 81.09 & 84.16 & 76.82 & 76.33 \\
& Color & 78.28 & 83.45 & 74.27 & 72.56 \\
& Giardia & ND & ND & ND & ND \\
& Cryptosporidium & ND & ND & ND & ND \\
& pH & 7.38 & 7.85 & 7.36 & 7.81 \\
\hline \multirow{2}{*}{ CFM-MF } & Turbidity & 93.54 & 92.28 & 84.78 & 99.39 \\
& Color & 96.15 & 92.19 & 88.96 & 100.0 \\
& Giardia & ND & ND & ND & ND \\
& Cryptosporidium & ND & ND & ND & ND \\
& pH & 7.33 & 7.72 & 7.34 & 7.51 \\
\hline
\end{tabular}

ND - not detected.

Table 4. Removal efficiencies of turbidity, color, Giardia and Cryptosporidium, and $\mathrm{pH}$ values of the water treated by the MF and CFM-MF processes.

It can be observed that the largest color and turbidity removals occurred with the combined CFM-MF process, compared with the MF process without pretreatment. There were no changes in the $\mathrm{pH}$ of the treated water. It is clear that the use of coagulation/flocculation with moringa prior to microfiltration improves the quality of treated water.

Few studies were found in the literature regarding the CF/MF process using moringa as a coagulant for surface water treatment. Madrona (2010) evaluated the combined process of coagulation/flocculation with moringa and MF with ceramic membranes, and obtained 97 to $100 \%$ removal of turbidity and color in the treatment of surface water from the Pirapó River, in Maringá, Paraná. These results were similar to those obtained in the present study, which used a polymer membrane for the MF process. Parker et al. (1999), using hollow fiber MF membranes with $0.2 \mu \mathrm{m}$ pores for the treatment of water that had been previously treated in settling tanks, obtained water with turbidity below 0.1 NTU, with average removal of $99.46 \%$, similar to those obtained in this study.

Neither in the microfiltration (MF) process alone, nor in the combined (CFM-MF) processes, (oo)cysts of Giardia and Cryptosporidium were detected in the filtered water, being below the detection limit (<1 cyst or oocyst/L) (approximately 6 log removal), in agreement with literature data. Jacangelo et al. (1995), studying the application of three MF membranes with pore sizes between 0.08 and $0.22 \mu \mathrm{m}$ for the treatment of water contaminated with Giardia and Cryptosporidium, found that the protozoa concentration was below detectable levels in the filtered water $(<1$ cyst or oocyst/L) from two of the membranes (corresponding to log removal $>4.7$ to $>7.0$ for Giardia and $>4.4$ to $>6.9$ for Cryptosporidium). They also concluded that the level of removal depends on the concentration of protozoa in the water to be treated 
and on membrane integrity. In another study, MF membranes with average pore size of 0.2 $\mu \mathrm{m}$ resulted in significant removal of particles that were the same size as Giardia cysts (5-15 $\mu \mathrm{m})$. Log removal was, on average, 3.3 to 4.4 . The removal of particles that were the same size as Cryptosporidium oocysts $(2-5 \mu \mathrm{m})$ was lower, 2.3 to $3.5 \mathrm{log}$ removal. These removals were obtained according to the concentration of (oo)cysts used for artificial contamination of water and proved to be independent of the membrane flux (114-170 L/hm²) (Karimi et al., 1999).

Thus, one can say that MF may act as a barrier against protozoan (oo)cysts. The coagulation/flocculation with moringa associated with microfiltration resulted in high levels of removal of the evaluated parameters.

Figure 3 shows the permeate flux versus time for the microfiltration of deionized water (DW), raw water without coagulant (SW), and pretreated water (CFM).

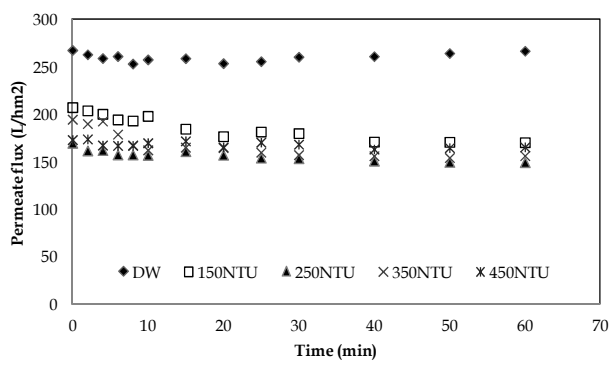

(a)

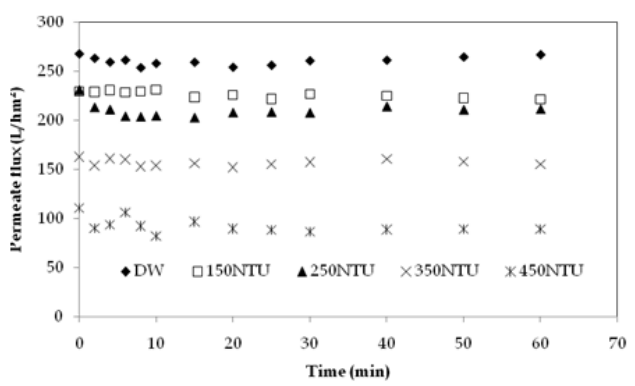

(b)

Source: Nishi, 2011.

Figure 3. Permeate flux with deionized water (DW) and raw water with initial turbidity from 150 to 450 NTU in the MF (a) and CFM-MF (b) processes.

For the MF process with raw water, that is, without previous treatment (coagulation/ flocculation), permeate flux ranged from 157 to $187 \mathrm{~L} / \mathrm{hm}^{2}$ for water samples of turbidity from 150 to $450 \mathrm{NTU}$. In the combined process (CFM-MF), permeate flux ranged from 157 to $226 \mathrm{~L} / \mathrm{hm}^{2}$ for water samples with initial turbidity of 150 to 350 NTU. Samples of 450 NTU presented the lowest permeate flux, $91 \mathrm{~L} / \mathrm{hm}^{2}$, on average (Nishi, 2011). This may be due to the presence of a greater number of particles that can cause the process of concentration polarization and due to superposition of various fouling mechanisms in the membrane, which may cause the decrease of the permeate flux (Stopka et al., 2001).

The combined processes of coagulation/flocculation/microfiltration showed slightly higher fluxes when compared with the microfiltration process alone. The improvement in permeate flux using coagulation/flocculation prior to microfiltration was also observed in other studies (Katayon et al., 2007; Horčičková et al., 2009).

The percentage of fouling $(\% \mathrm{~F})$ for the MF process with raw water (SW) and water coagulated/flocculated with moringa (CFM) with initial turbidity from 150 to $450 \mathrm{NTU}$ is shown in Figure 4. 


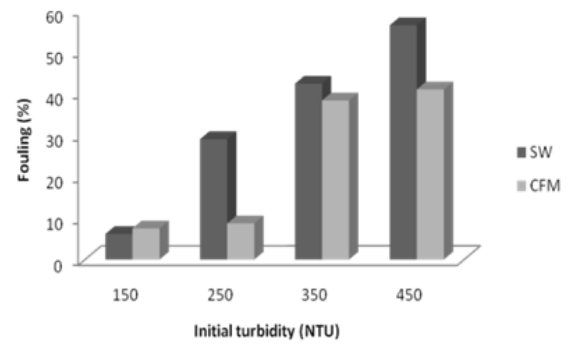

Figure 4. Percentage of fouling for the MF process with superficial water (SW) and water coagulated/flocculated with moringa (CFM) with initial turbidity from 150 to 450 NTU.

It is observed that the MF process with raw water showed higher percentages of fouling, ranging from 6.13 to $56.32 \%$ when compared with the combined process of coagulation/ flocculation with moringa followed by MF, which presented percentages of fouling from 7.48 to $40.9 \%$ (Nishi , 2011). This reduction in membrane fouling when using the process of coagulation/flocculation as pretreatment was also observed in other studies. Madrona (2010) used coagulation/ flocculation with moringa, followed by MF with ceramic membranes with porosity of 0.1 and $0.2 \mu \mathrm{m}$, for the treatment of surface water and observed fouling percentages of around $94 \%$ during the filtration of raw water and slightly lower values, around $88 \%$, when water previously coagulated/flocculated with moringa was filtered. Carroll et al. (2000) used polypropylene hollow fiber MF membrane to filter surface water from the Moorabool River, Australia, and observed fouling percentages of $80 \%$ for water without pretreatment and $50 \%$ for water pretreated by coagulation with alum.

According to Cheryan (1998), the type and extent of fouling depend on the chemical nature of the membrane, the solute, and the solute-membrane interactions, as well as on the porosity of the membrane and the working pressure used in the process.

\section{Conclusion}

It was possible to conclude that the coagulation with moringa performed satisfactory results, reducing the number of (oo)cysts of protozoan parasites in the study, $1.2 \log$ removal for Giardia and $1.0 \mathrm{log}$ removal for Cryptosporidium, which is in accordance with the WHO recommendations for the coagulation / flocculation process.

Furthermore, there was a reduction on turbidity and color approximately $97 \%$ and the $\mathrm{pH}$ remained stable in all water samples treated with moringa.

The combined process, coagulation/flocculation/microfiltration sequence, removed almost $100 \%$ of Giardia and Cryptosporidium (oo)cysts, besides the high color and turbidity removal (above $90 \%$ ) of the water samples treated by the proposed process, with the advantage of improving the quality of filtered water and to improve the characteristics of the MF process, noting that the use of pretreatment with the coagulant moringa before the MF reduces the membrane fouling and slightly increases the permeate flow. 
The use of M. oleifera Lam seeds can be considered advantageous and a promising step towards improving the processes of water coagulation/flocculation followed by microfiltration.

\section{List of abbreviations}

Coagulation/flocculation $=\mathrm{CF}$

Coagulation/flocculation using moringa as coagulant $=\mathrm{CFM}$

Coagulation/flocculation using moringa as coagulant followed by microfiltration $=\mathrm{CFM}-\mathrm{MF}$ Microfiltration $=\mathrm{MF}$

Moringa oleifera $=$ moringa

Natural organic matter $=$ NOM

\section{Author details}

Letícia Nishi, Angélica Marquetotti Salcedo Vieira, Ana Lúcia Falavigna Guilherme, Milene Carvalho Bongiovani, Rosângela Bergamasco

Universidade Estadual de Maringá, Brazil

Gabriel Francisco da Silva

Universidade Federal de Sergipe, Brazil

\section{Acknowledgement}

The authors acknowledge the financial support provided by the research agency National Counsel of Technological and Scientific Development (CNPq).

\section{References}

Akhtar, M., Moosa Hasany, S., Bhanger, M. I. \& Iqbal, S. (2007). Sorption potential of Moringa oleifera pods for the removal of organic pollutants from aqueous solutions. Journal of Hazardous Materials, Vol. 141, No. 3, pp. 546-556.

Aldom, J.E. \& Chagla, A.H. (1995). Recovery of Cryptosporidium oocysts from water by a membrane filter dissolution method. Letters in Applied Microbiology, Vol. 20, pp. 186-187.

American Public Health Association [APHA]. [1995]. Standard Methods for the Examination for Water and Wastewater (19th edition). Byrd Prepess Springfield, ISBN 0875532233, Washington.

Andrade Neto, J.L. \& Assef, M.C.V. (1996). Criptoporidiose e Microsporidiose. In: Tratado de Infectologia. Focaccia, R. \& Veronesi, R. (ed.), p.1170, Atheneu, ISBN 8538801015, São Paulo.

Assavasilavasukula, P., Lau, B.L.T., Harrington, G.W., Hoffman, R.M. \& Borchardt, M.A. (2008). Effect of pathogen concentrations on removal of Cryptosporidium and Giardia by conventional drinking water treatment. Water Research, Vol. 42, pp. 2678-2690. 
Balakrishnan, M., Dua, M. \& Khairnar, P.N. (2001). Significance of membrane type and feed stream in the ultrafiltration of sugarcane juice. Journal of Separation Science and Technology, Vol. 36, No. 4, pp. 619-637.

Bhatia, S., Othman, Z. \& Ahmad, A.L. (2007). Pretreatment of palm oil mill effluent (POME) using Moringa oleifera seeds as natural coagulant. Journal of Hazardous Materials, Vol. 145, No. 1-2, pp. 120-126.

Bergamasco, R., Konradt-Moraes, L.C., Vieira, M.F., Fagundes-Klen, M.R. \& Vieira, A.M.S. (2011). Performance of a coagulation-ultrafiltration hybrid process for water supply treatment. Chemical Engineering Journal, Vol. 166, pp. 483-489.

Bertrand, I. \& Schwartzbrod, J. (2007). Detection and genotyping of Giardia duodenalis in wastewater: relation between assemblages and faecal contamination origin. Water Research, Vol. 41, No. 16, pp. 3675-3682.

Bouzid, M., Steverding, D. \& Tyler, K.M. (2008). Detection and surveillance of waterborne protozoan parasites. Current Opinion in Biotechnology, Vol. 19, pp. 302-306.

Brown, T.J. \& Emelko, M.B. (2009). Chitosan and metal salt coagulant impacts on Cryptosporidium and microsphere removal by filtration. Water Research, Vol. 43, pp. 331338.

Bustamante, H.A., Shanker, S.R., Pashley, R.M. \& Karaman, M.E. (2001). Interaction between Cryptosporidium oocysts and water treatment coagulants. Water Research, Vol. 35, pp. 3179-3189.

Butler, B.J.\& Mayfield, C.I. (1996). Cryptosporidium spp. - A review of the organism, the disease, and implications for managing water resources. Waterloo Centre for Groundwater Research, Waterloo., Ontario: Canada.

Cacciò, S., Thompson, R.C., Mclauchlin, J. \& Smith, H.V. (2005). Unravelling Cryptosporidium and Giardia epidemiology. Trends in Parasitology, Vol. 21, pp. 430-437.

Campbell, I., Tzipori, S., Hutchison, G.E. \& Angus, K.W. (1982). Effect of disinfectants on survival of Cryptosporidium oocysts. Veterinary Record, Vol. 3, pp. 414-415.

Cantusio Neto, R. \& Franco, R.M.B. (2004). Ocorrência de oocistos de Cryptosporidium spp. e cistos de Giardia spp. em diferentes pontos do processo de tratamento de água, em Campinas, São Paulo, Brasil. Revista Higiene Alimentar, Vol. 118, pp. 52-59.

Cardoso, K.C., Bergamasco, R., Cossich, E.S. \& Konradt-Moraes, L.C. (2008). Otimização dos tempos de mistura e decantação no processo de coagulação/floculação da água bruta por meio da Moringa oleifera Lam. Acta Scientiarum - Technology, Vol. 30, pp. 193-198.

Carroll, T., King, S., Gray, S. R., Bolto, B. A. \& Booker, N. A. (2000). The fouling of microfiltration membranes by nom after coagulation treatment. Water Research, Vol. 34, No. 11, pp. $2861-2868$.

Centers for Disease Control and Prevention [CDC]. (2006). Surveillance Summaries, December 22. MMWR, 55 (No SS-12).

Cheryan, M. (1998). Ultrafiltration and microfiltration handbook. Technomic Publishing CO, Illinois, Lancaster, USA.

Chuang, P.H., Lee, C.W., Chou, J.Y., Murugan, M., Shieh, B.J. \& Chen, H.M. (2007). Antifungal activity of crude extracts and essential oil of Moringa oleifera Lam. Bioresource Technology, Vol. 98, pp. 232-236. 
Coelho, J.S., Santos, N.D.L., Napoleão, T.H., Gomes, F.S., Ferreira, R.S., Zingali, R.B., Coelho, L.C.B.B., Leite, S.P., Navarro, D.M.A.F. \& Paiva P.M.G. (2009). Effect of Moringa oleifera lectin on development and mortality of Aedes aegypti larvae. Chemosphere, Vol. 77, No. 7, pp. 934-938.

Consonery, P.J., Greenfield, D.N. \& Lee, J.J. (1997). Pennsylvania's filtration evaluation programme. Journal of the American Water Works Association, Vol. 89, pp. 67-77.

Dawson, D.J., Maddocks, M., Roberts, J. \& Vidler, J.S. (1993). Evaluation of recovery of Cryptosporidium parvum oocysts using membrane filtration. Letters in Applied Microbiology, Vol. 17, pp. 276-279.

Fayer, R. \& Ungar, B.L.P. (1986). Cryptosporidium spp and cryptosporidiosis. Microbiology Reviews, Vol. 50, pp. 458-484.

Fayer, R., (1997). Cryptosporidium and cryptosporidiosis. Boca Raton: CRC Press, p. 251.

Fayer, R., Morgan, U. \& Upton, S.J. (2000). Epidemiology of Cryptosporidium: transmission, detection and identication. International Journal for Parasitology, Vol. 30, pp. 1305-1322.

Fayer, R. (2004). Cryptosporidium: a water-borne zoonotic parasite. Veterinary Parasitology, Vol. 126, pp. 37-56.

Franco, R.M.B., Rocha-Eberhardt, R. \& Cantusio Neto, R. (2001). Occurrence of Cryptosporidium oocysts and Giardia cysts in raw water from the Atibaia river, Campinas, Brazil. Rev. Inst. Med. Trop. S. Paulo, Vol. 43, No. 2, pp. 109-111.

Fundação Nacional de Saúde (National Health Foundation) [FUNASA]. Toxic cyanobacterias in water for human consumption in public health, and process for their removal from water for human consumption. Ministry of Health, Brasília, (2003) 56 pp. (In Portuguese).

Furtado, C., Adak, G.K., Stuart, J.M., Wall, P.G., Evans, H.S. \& Casemore, D.P. (1998). Outbreaks of waterborne infectious intestinal disease in England and Wales, 1992-5. Epidemiology and Infection, Vol. 121, pp. 109-119.

Ghebremichael, K.A., Gunaratna, K.R., Henriksson, H., Brumer, H. \& Dalhammar, G. (2005). A simple purification and activity assay of the coagulant protein from Moringa oleifera seed. Water Research, Vol. 39, No. 11, pp. 2338-2344.

Haas, C.N. \& Kaymak, B. (2003). Effect of initial microbial density on inactivation of Giardia muris by ozone.Water Research, Vol. 37, pp. 2980-2988

Helmi, K., Skraber, S., Gantzer, C., Willame, R., Hoffmann, L. \& Cauchie, H.M. (2008). Interactions of Cryptosporidium parvum, Giardia lamblia, vaccinal poliovirus type 1, and bacteriophages phiX174 and MS2 with a drinking water biofilm and a wastewater biofilm. Applied and Environmental Microbiology, Vol. 74, pp. 2079-2088.

Horčičková, J., Mikulášek, P. \& Dvořáková, J. (2009). The effect of pre-treatment on crossflow microfiltration of titanium dioxide dispersions. Desalination, Vol. 240, pp. 257261.

Hsu, B.M. \& Huang, C. (2002). Influence of ionic strength and $\mathrm{pH}$ on hydrophobicity and zeta potential of Giardia and Cryptosporidium. Colloids and Surfaces A: Physicochemical and Engineering Aspects, Vol. 201, pp. 201-206.

Iacovski, R.B., Barardi, C.R.M. \& Simões, C.M.O. (2004). Detection and enumeration of Cryptosporidium sp. oocysts in sewage sludge samples from the city of Florianópolis 
(Brazil) by using immunomagnetic separation combined with indirect immunofluorescence assay. Waste Management E Research, Vol. 22, pp. 171-176.

Jacangelo, J. G., Adham, S. S. \& Laîné, J-M. (1995). Mechanism of Cryptosporidium, Giardia and MS2 virus removal by MF and UF. Journal of the American Water Works Association, Vol. 87, No. 9, pp. 107-121.

Karimi, A.A., Vickers, J.C. \& Harasick, R.F. (1999). Microfiltration goes Hollywood: the Los Angles experience. Journal of the American Water Works Association, Vol. 91, No. 6, pp. 90103.

Karanis, P., Kourenti, C. \& Smith, H. (2007). Water-borne transmission of protozoan parasites: a review of world-wide outbreaks and lessons learnt. Journal of Water and Health. 5: 1-38.

Katayon, S., Noor, M.J.M.M., Asma, M., Ghani, L.A.A., Thamer, A.M., Azni, I., Ahmad, J., Khor, B.C. \& Suleyman, A.M. (2006). Effects of storage conditions of Moringa oleifera seeds on its performance in coagulation. Bioresource Technology, Vol. 97, No. 13, pp. 1455-1460.

Khalifa, A.M., El Temsahy, M.M. \& Abou El Naga, I.F. (2001). Effect of ozone on the viability of some protozoa in drinking water. Journal of the Egyptian Society of Parasitology, Vol. 31, pp. 603-616.

Korich, D.G., Mead, J.R., Madore, M.S., Sinclair, N.A. \& Sterling, C.R. (1990). Effects of ozone, chlorine dioxide, chloride, and monochloramine on Cryptosporidium parvum oocyst viability. Applied and Environmental Microbiology, Vol. 56, pp. 1423-1428.

Lindquist, A. (1999). Emerging pathogens of concern in drinking water. United States Environmental Protection Agency, EPA, 600/R-99/070.

Madrona, G.S., Serpelloni, G.B., Vieira, A.M.S., Nishi, L., Cardoso, K.C \& Bergamasco, R. (2010). Study of the effect of saline solution on the extraction of the Moringa oleifera seed's active component for water treatment. Water, Air, \& Soil Pollution, Vol. 211, pp. 409-415.

Medema, G., Teunis, P., Blokker,M., Deere, D., Davison, A., Charles, P. \& Loret, J.F. (2006). WHO Guidelines for Drinking Water Quality, Environmental Health Criteria, Cryptosporidium, Draft 2.

Muller, A.P.B., 1999, Detecção de oocistos de Cryptosporidium spp em águas de abastecimento superficiais e tratadas da região metropolitana de São Paulo. Dissertação de Mestrado, Instituto de Ciências Biomédicas da USP - São Paulo (in portuguese).

Ndabigengesere A., Narasiah, S.K. \& Talbot, B.G. (1995). Active agents and mechanism of coagulation of turbid waters using Moringa oleifera, Water Research, Vol. 29, No. 2, pp. 703-710.

Ndabigengesere, A. \& Narasiah, K.S. (1998). Quality of water treated by coagulation using Moringa oleifera seeds. Water Research, Vol. 32, pp. 781-791.

Neves, D.P. (2005). Parasitologia humana. Atheneu. ISBN 8573797371. São Paulo.

Nishi, L. (2011). Estudo dos processos de coagulação/floculação seguido de filtração com membranas para remoção de protozoários parasitas e células de cianobactérias. Doctoral Thesis, Universidade Estadual de Maringá - Maringá, PR, Brasil, 203 pp. (in Portuguese). 
Nkurunziza, T., Nduwayezu, J.B., Banadda, E.N. \& Nhapi, I. (2009). The effect of turbidity levels and Moringa oleifera concentration on the effectiveness of coagulation in water treatment. Water Science and Technology, Vol. 59, pp. 1551-1558.

Okuda, T., Baes, A.U., Nishijima, W. \& Okada, M. (1999). Improvement of extraction method of coagulation active components from Moringa oleifera seed. Water Research, Vol. 33, No. 15, pp. 3373-3378.

Okuda, T., Baes, A.U., Nishijima, W. \& Okada, M. (2001). Isolation and characterization of coagulant extracted from Moringa oleifera seed by salt solution. Water Research, Vol. 35, No. 2, pp. 405-410.

Ortega, Y.R., Roxas, C.R., Gilman, R.H., Miller, N.J., Cabrera, L., Taquiri, C. \& Sterling, C.R. (1997). Isolation of Cryptosporidium parvum and Cyclospora cayetanensis from vegetables collected in markets of a endemic region in Peru. The American Journal of Tropical Medicine and Hygiene, Vol. 57, No. 6, pp. 683-686.

Parker, D. Y., Leonard, M. J., Barber, P., Bonic, G., Jones W. \& Leavell, K. L. (1999). Microfiltration treatment of filter backwash recycle water from a drinking water treatment facility. Proceedings of the American Water Works Association Water Quality Technology Conference. Denver, CO, American Water Works Association.

Peeters, J.E., Ares Mazás, E., Masschelein, W.J., Villacorta-Martinez De Maturana, I. \& Debacker, E. (1989). Effect of disinfection of drinking water with ozone or chlorine dioxide on survival of Cryptosporidium parvum oocysts. Applied and Environmental Microbiology, Vol. 55, pp. 1519-1522.

Plutzer, J., Ongerth, J. \& Karanis, P. (2010). Giardia taxonomy, phylogeny and epidemiology: facts and open questions. International Journal of Hygiene and Environmental Health, Vol. 213, pp. 321-333.

Ramos, R.O. (2005). Clarification of water with low turbulence and moderate color using seeds of Moringa oleifera. State University of Campinas, Campinas-SP, Brazil. 276 pages. (Doctoral Thesis; in Portuguese).

Rey, L. (2001). Parasitologia. Guanabara Koogan. ISBN 9788527714068 .Rio de Janeiro.

Robertson, L.J., Campbell, A.T. \& Smith, H.V. (1992). Survival of Cryptosporidium parvum oocysts under various environmental pressures. Applied and Environmental Microbiology, Vol. 58, pp. 3494-3500.

Robertson, L., Gjerde, B., Hansen, E.F. \& Stachurska-Hagen, T. (2009). A water contamination incident in Oslo. Norway during October 2007; a basis for discussion of boil-water notices and the potential for post-treatment contamination of drinking water supplies. Journal of Water and Health, Vol. 7, pp. 55-66.

Rondeau, V., Commenges, D., Jacqmin-Gadda, H. \& Dartigues, J.F. (2000). Relation between aluminum concentrations in drinking water and Alzheimer's disease: an 8-year followup study. American Journal of Epidemiology, Vol. 152, pp. 59-66.

Rose, J.B. (1990). Occurrence and control of Cryptosporidium in drinking water. In: Drinking Water Microbiology. p. 294-321.Springer-Veriag, New York.

Smith, H.V. \& Rose, J.B. (1998). Waterbome cryptosporidiosis: current status. Parasitology Today, Vol. 14, pp. 14-22. 
Sterling, C.R. (1990). Waterborne Cryptosporidiosis. In: Cryptosporidiosis in Man and Animals. Dubey, J.P., Speer, C.A. \& Fayer, R. Ed. CRC Press, Boca Raton, FL. p. 51-59.

Stopka, J., Bugan, S. G. \& Broussous, L. (2001). Microfiltration of beer yeast suspensions through stamped ceramic membranes. Separation and Purification Technology, Vol. 25, pp. 535-543.

Thompson, R.C.A. (2000). Giardiasis as a re-emerging infectious disease and its zoonotic potential. International Journal of Parasitology, Vol. 30, pp. 1259-1267.

Thompson, R.C.A. (2004). The zoonotic significance and molecular epidemiology of Giardia and giardiasis. Veterinary Parasitology, Vol. 126, pp. 15-35.

United States Environmental Protection Agency [USEPA]. 1996. National Primary Drinking Water Regulations: Monitoring Requirements for Public Drinking Water Supplies; Final Rule. 40CFR Part 141.

Vieira, A.M.S., Vieira, M.F., Silva, G.F., Araújo, A.A., Fagundes-Klen, M.R., Veit, M.T. \& Bergamasco, R. (2010). Use of Moringa oleifera Seed as a Natural Adsorbent for Wastewater Treatment. Water, Air, E Soil Pollution, Vol. 206, pp. 273-281.

Von Gunten, U. (2003). Ozonation of drinking water. Part II. Disinfection and by-product formation in presence of bromide, iodide or chlorine. Water Research, Vol. 37, pp. 14691487.

Xagoraraki, I. \& Harrington, G.W. (2004). Zeta potential, dissolved organic carbon, and removal of Cryptosporidium oocysts by coagulation and sedimentation. Journal of Environmental Engineering, Vol. 130, pp. 1424-1432.

Xiao, L. (2010). Molecular epidemiology of cryptosporidiosis: an update. Experimental Parasitology, Vol. 124, pp. 80-89. 